\title{
Exploring the Virtual Experiment Teaching of Computer Graphics Xie-Qiu Zhao ${ }^{1, a}$, Zai-yong Song ${ }^{1, b}{ }^{*}$,Feng Xiong ${ }^{2}$ \\ ${ }^{1}$ College of Computer Science Technology, BeiHua University, China \\ Scientific research division of Beihua University \\ ${ }^{2}$ China University of Petroleum(Beijing), China \\ abhjsj@126.com,
}

\begin{abstract}
Keywords: Computer Graphics; Virtual Reality Technology; Computer Experiment; Teaching
\end{abstract} Methods

\begin{abstract}
With the development of computer graphics, in order to enhance the effect of experiment teaching computer graphics, this paper puts forward the virtual experiment into experimental teaching process aimed at computer graphics algorithm complex problems, the virtual object associated with abstract objects involving graphics computer graphics algorithms, simulation algorithm is used to process the virtual scene, abstract objects and algorithms the process of visualization. visualization of abstract objects and computation process make the abstract algorithm easily to be understood, which will achieve the purpose of improving teaching effect, and provide certain reference computer graphics for teaching workers .
\end{abstract}

\section{The importance of computer graphics teaching}

With the development of information technology, more and more concern has been paid to the theories and methods related to computer graphics. The development of computer software and hardware and the wide application of computer graphics API function result in computer graphics has become one of the most active and widely been used branches in computer science. Computer graphics is a discipline that studies and discusses how to convert data into graphics and display them on a display terminal by computer. Comparing with plain text, the information carried by graphics are rich and colorful. the rapid development of digital graphics application in various fields which include people's work and life, aerospace and aircraft design, the car's shape atmospheric forecast, film and television advertising, games, video phone, WeChat, etc. ,which become wonderful due to the application of computer graphics technology[1] .

At present, most colleges and universities in the computer and related major set up "computer graphics" course which one of the important courses of computer and related major as well as. This course emphasizes both theory and practice, and it is also a pre-course of practical courses, such as digital image and pattern recognition, 3D animation programming. Therefore, students are curious and expecting for the course of computer graphics.

\section{The characteristics of computer graphics course, the existing problems in the teaching process and the teaching reform}

\subsection{Characteristics of computer graphics course}

First of all, involving extensive content is one of the characteristics of computer graphics course. Computer graphics is a multidisciplinary and comprehensive curriculum, which includes the hardware and software of computer, space analytic geometry, calculation method, partial differential equations, optimization, probability, statistics, computational geometry, algorithm principle and programming theory, basic requirement is high, the teaching effect is poor, so many students are required to have knowledge. Such as good mathematical basis, especially the basic knowledge of mathematical analysis, such as space analytic geometry, linear algebra, matrix theory, computer language programming, data structure and so on[2]. Secondly, there are many teaching contents and 
scattered knowledge points. The theory involved in the course needs a certain mathematical basis to understand better, and a large number of abstract graphics generation algorithms increase the difficulty of learning. Therefore, to strengthen students' mathematical theory learning is the most basic requirement of graphics.

The principle and method of computer graphics involves a lot of teaching content, easy to cause students to master everything, only scattered knowledge, did not form a complete chain of knowledge, students learn the knowledge of a loss, lose the goal of learning, which greatly affects the learning enthusiasm of students; at the same time, the principle of the algorithm is limited to the classical teaching content the frontier subject, dynamic involved less, is not conducive to broaden their horizons, stimulate their awareness of autonomous learning and interest, both theoretical and experimental courses[3]. The process of describing and realizing graphics problems in computer language. That is, it includes computer language and graphics knowledge. Generally speaking, the basic algorithm to describe graphics related to the understanding of students' learning is a difficult problem in computer graphics, is a cognitive process from theory to practice, the boring algorithm requires virtual graphics more intuitive to reflect.

\subsection{Existing problems}

Due to the characteristics of computer graphics courses. In the teaching process, students generally reflect: can realize computer graphics is an important and useful and practical courses, the course began to learn computer graphics with great interest in learning, however, with the in-depth study of the curriculum, graphics algorithm is more and more complicated, though the principle and process of the classroom can understand the algorithm, but the algorithm is difficult after school on, not a good combination of theory and practice[4]. With the passage of time, accumulated can not solve the problem, the old content does not understand, does not solve the problem, but also busy learning new content, learning has become a kind of pressure, enthusiasm and confidence hit, learning initiative gradually decreased, as a result, the teaching effect is not ideal. In short, students feel that the content of graphics is not easy to understand, wide range, theory and experiment is always a certain distance

\subsection{Reform of teaching methods}

In order to solve the teaching problems, to improve the teaching quality of computer graphics, received a better teaching effect, many computer graphics of the teachers in the teaching experiment, classroom teaching with different teaching methods, have achieved good teaching effect.

The content of computer graphics, the emphasis and difficulty will involve complex algorithm, and these contents for students, is the most difficult to understand, the conventional teaching method, its effect is relatively low, therefore, computer graphics in the process of teaching, different teaching contents should be selected, and can receive the better the teaching effect of the use of appropriate teaching methods, so as to maximize the efficiency of teaching methods, teaching methods to achieve accurate. In order to realize the accurate application of the teaching method in the teaching of computer graphics, so the algorithm involves complex content in the teaching process, make full use of the existing equipment, the introduction of virtual reality technology, process and operation mechanism of a complex algorithm for 3D interactive technology are described, the complex algorithm specific, simple, easy to understand. The theory and experiment both the better understanding, better grasp the emphases and difficulties of learning computer graphics, grasp the key to learn computer graphics, to resolve the problem in the process of learning. The graphics in virtual reality applications, you can insert a video, animation, simulation of human walking in the virtual scene, through changing all kinds of images of the scene, can not only explain the specific application, and easy for students to accept, impressive[5]. 


\section{Computer graphics virtual reality technology teaching reform}

\subsection{The necessity and importance of introducing virtual reality technology into classroom teaching of computer graphics}

To realize the combination of theory and practice, we must first fully understand the principle of the algorithm, the core of the algorithm, the process. However, most computer graphics algorithms are based on mathematical theory, students are required to have such as basic analytic geometry, linear algebra, matrix theory and application of mathematical knowledge, in other words, a good mathematical foundation, is a favorable condition to learn computer graphics algorithm. And good mathematical foundation, need through professional training[6]. In general, students are not very good at math, which is why students are relatively difficult to learn algorithms. In this case, the algorithm in the teaching process, to replace the traditional blackboard chalk and the use of modern information technology, simulation algorithm is the introduction of computer technology, the description of the algorithm and the realization process of a specific image, it is through virtual reality technology, the abstract algorithm into the virtual environment for animation, let the students easy to accept and understand, so as to stimulate the enthusiasm of students, to achieve the best teaching effect, make full preparations for students after school on algorithm, realized the combination of theory and practice. Therefore, it is necessary to introduce virtual reality technology into the teaching process.

\subsection{Introduction of virtual reality technology into the teaching of computer graphics}

In the process of teaching, the abstract, invisible mathematical model and general virtual reality technology are used to make it concrete and visualized. The specific implementation process will be as follows: algorithm decomposition, with the method of virtual technology will step in the operation of the algorithm and the intermediate results step by step demonstration, to the form of courseware in classroom presentation, let students establish the corresponding mathematical model of the relationship between the algorithm and code, to more deeply understand the principle and algorithm of various graphics the implementation process. In this paper, Virtualbox5.2 ten 3DMAX is chosen as the development environment of courseware. 3DMax has strong modeling function, the graphics algorithm calculation unit in the process (memory function, etc.) geometry in the virtual experiment scene in correspondence with a simple (cube, cylinder and sphere) said in a single scene, 3D m ax can achieve rapid and efficient modeling in addition, 3DM ax, with many mass modeling tools, such as the use of mirror, dispersion, array and other tools, can realize more precise (coordinate geometry modeling), fully meet the needs of graphics virtual experiment scene modeling. Virtualbox5.2 is a relatively mature with 3D interactive finally synthesis software, its good compatibility and highlight the advantages of virtual scene and animation by directly into the corresponding plug-in converted output 3D Max construction, support multi scene features in Virtualbox5.2, can realize interactive function switching, multi jump between the virtual scene, the expression is more clear and more obvious, showing the virtual experiment is intuitive, interactive, easy to understand the advantages of graphic transformation.

The implementation process: the graphics algorithm implementation process memory unit, relates to the variables and function entity in the virtual scene, in the virtual scene by a cube or a sphere, cylinder and so on, a graphics algorithm of virtual scenes, a single scene into Virtualbox5. 2 $3 \mathrm{D} \mathrm{m} \mathrm{A} \mathrm{X}$ built in the animation layout according to the process of the algorithm. Because Virtualbox5.2 supports multi scene function, according to the needs, will realize the process of complex graphics algorithm is decomposed into several sub processes of the algorithm, the relative performance of independent sub different algorithms with different scenes in Virtualbox5.2, which in the different scene layout corresponding scene animation realization algorithm, in the design of interactive interface the scene, scene between switching and jump, finally derived multi scene module, $3 \mathrm{D}$ virtual experiment courseware with interactive function. For the verification experiments, namely those representative algorithms, such as linear generation, clipping calculation, each student is required according to the experimental procedures for materials hands-on implementation, strengthen 
the basic algorithm of classroom understanding, cultivate their sense of achievement, and the requirements of the subject with the difficult degree of change, such as line generation algorithm is relatively simple, require students to achieve the algorithm must be general, at the same time, in order to increase the students' interest in learning, can the ingenious design of the experiment content, such as the implementation of linear algorithm, can let students draw the line graph transformation generated Chinese characters; mainly make students realize the transformation of two-dimensional graphics, including translation, rotation, zoom and composite transform and so on, because this experiment contains multiple operations, requiring students to increase the menu selection function; cutting calculation required to achieve line clipping The algorithm, starting from the easy operation angle, request algorithm using line drawing method for interactive; curve generation algorithm require students to the method according to the parameter curve defined to realize, for the programming ability of students, to achieve animation effects by programming in curve generation.

\section{Summary}

Based on the actual situation of computer graphics experimental teaching of digital media technology specialty in our university, based on the mode of "applied talents training", the experimental teaching methods and content settings were reformed. At the same time, the experiment environment, content and experimental items were re arranged and arranged. Practice has proved that the method proposed in this paper has a significant effect on deepening the understanding of curriculum, cultivating students' interest and improving the quality of teaching. Computer graphics is a developing cross discipline, and its teaching methods need to be explored continuously in practice. The introduction of virtual reality technology to effectively promote the teaching of computer graphics, special emphasis and difficulty in computer graphics, such as teaching content of graphics algorithm, obviously improve the teaching effect, through interactive graphics make students easy to understand the concept of graphics, mobilize the enthusiasm of students, improve students' practical ability. The introduction of virtual reality technology into the teaching of computer graphics provides a new solution to the key and difficult points in the teaching of computer graphics. It is a new attempt. We also study the efficient teaching in teaching methods and teaching methods at the same time, should also actively participate in the teaching contents of related research work, thus more clearly the emphasis and difficulty of teaching, be targeted in the process of teaching, enthusiasm and initiative to stimulate students' thinking and learning.

\section{Acknowledgment}

The research work is supported by the 13th five-year science and technology project of the education department of jilin province (No. JJKH20170033KJ).

\section{References}

[1] Yan Shenghua. Computer graphics teaching research and practice [J]. computer education, 2010,10 (13); 114-116.

[2] Zhao Qinping. Virtual reality summary [J]. Chinese Science (F: Information Science), 2009,39 (1) 2-4.

[3] Computer graphics [M]. 2nd edition. Beijing: Mechanical Industry Press, 2009: 2.

[4] Pan Jisheng, where reinforcements, Zhao Junying. Computer graphics teaching research and practice [R]. Yantai: the first session of the general assembly, Chinese graphics, 2007: 476-479.

[5] Wu Xu ,Shaoping, propofol, Chuan Jie. For computer graphics teaching based on OpenGL Courseware [J]. computer and modernization, 2007 (9): 114-119.

[6] Liu Jingang, Kong Lingde, Wang Jinzhong. Research and practice of new teaching model of computer graphics course [J]. computer education, 2010 (3): 63-65. 